\title{
Biologia da Conservação: ciência da crise
}

\section{Conservation Biology; a crisis science}

\author{
Efraim Rodrigues, Ph.D. ${ }^{1}$
}

\section{Resumo}

A ciência da Biologia da Conservação foi desenvolvida como uma resposta à crise de extinção de espécies que o mundo enfrenta atualmente. A Biologia da Conservação é uma síntese de diferentes disciplinas, como Ecologia, Biologia de Populações, Antropologia, Taxonomia, e outras, todas enfocadas na prevenção da extinção de espécies. O Desenvolvimento de uma Biologia da Conservação Brasileira depende de encontrar um compromisso entre os problemas sociais e a grande biodiversidade no país. Três projetos que conseguiram alcançar bons resultados no Brasil são descritos. O Projeto TAMAR, o Mamirauá, e um livro texto sobre biologia da conservação.

Palavras-Chave: Biologia da conservação, espécies brasileiras

\begin{abstract}
The science of conservation biology has been developed as an answer to the extinction crisis the world is currently facing. Conservation Biology is a synthesis of many different subjects, like Ecology, Population Biology, Anthropology, Taxonomy, all of them focused on preventing species extinction. The development of a Brazilian Conservation Biology depends on finding a compromise between the social problems and the large biodiversity in the country. Three projects that managed to achieve good results in Brazil are described: TAMAR, Mamirauá, and a text book on conservation biology.
\end{abstract}

Key-Words: Conservation Biology, species Brazil

\section{A extinção de espécies e suas conseqüências}

$\mathrm{O}$ vasto patrimônio que é o conjunto de todas as espécies e comunidades naturais da Terra está sob risco iminente. Extintas as espécies, serão afetados também todos os processos naturais que que guardam relações com estas espécies, como ciclagem de nutrientes, erosão, polinização e dispersão de sementes.

O evento de mega-extinção por que passa nosso planeta coloca todo estes processos em risco, e junto com eles, muitas atividades humanas que dependem deles. A extinção de espécies implica em últi- ma instância, em aceleração do aquecimento global, em menor eficiência da agricultura e na redução do potencial turístico de muitas áreas.

Assim, o que é negativo para a diversidade biológica será mais cedo ou mais tarde negativo para a espécie humana.

\section{O que é Biologia da Conservação}

A biologia da conservação é uma ciência multidisciplinar que foi desenvolvida como resposta

\footnotetext{
${ }^{1}$ Professor Adjunto do Departamento de Agronomia da Universidade Estadual de Londrina.
} 
à crise com a qual a diversidade biológica se confronta atualmente (Figura 1). Ela surgiu uma vez que nenhuma das disciplinas tradicionais aplicadas são abrangentes o suficiente, para tratar das sérias ameaças à diversidade biológica. A biologia da agricultura, silvicultura, de gerenciamento da vida selvagem e da piscicultura ocupam-se basicamente do desenvolvimento de métodos para gerenciar umas poucas espécies para fins mercadológicos e de recreação. Essas disciplinas geralmente não tratam da proteção de todas as espécies encontradas nas comunidades ou as tratam como um assunto secundário. A biologia da conservação complementa as disciplinas aplicadas fornecendo uma abordagem mais teórica e geral para a proteção da diversidade biológica; ela difere das outras disciplinas porque leva em consideração, em primeiro lugar, a preservação a longo prazo de todas as comunidades biológicas e coloca os fatores econômicos em segundo plano.

As disciplinas de biologia populacional, taxonomia, ecologia e genética constituem a base da biologia da conservação e muitos biologistas de conservação procedem dessas disciplinas. Além disso, muitos dos especialistas em biologia da conservação foram treinados inicialmente em zoológicos e jardins botânicos trazendo consigo experiência em manter e reproduzir espécies em cativeiro. Uma vez que grande parte das extinções de espécies tem origem na pressão exercida pelo homem, a biologia da conservação também incorpora idéias e especificidades de várias outras áreas, além da biologia (Figura 1). Por exemplo, legislação e política ambiental dão sustentação à proteção governamental de espécies raras e ameaçadas e de habitats em situação crítica. A ética ambiental oferece fundamento lógico para a preservação das espécies. As ciências sociais tais como antropologia, sociologia e geografia fornecem a percepção de como as pessoas podem ser encorajadas e educadas para proteger as espécies encontradas em seu ambiente imediato. Os economistas ambientais analisam o valor econômico da diversidade biológica para sustentar argumentos em favor da preservação. Eco-

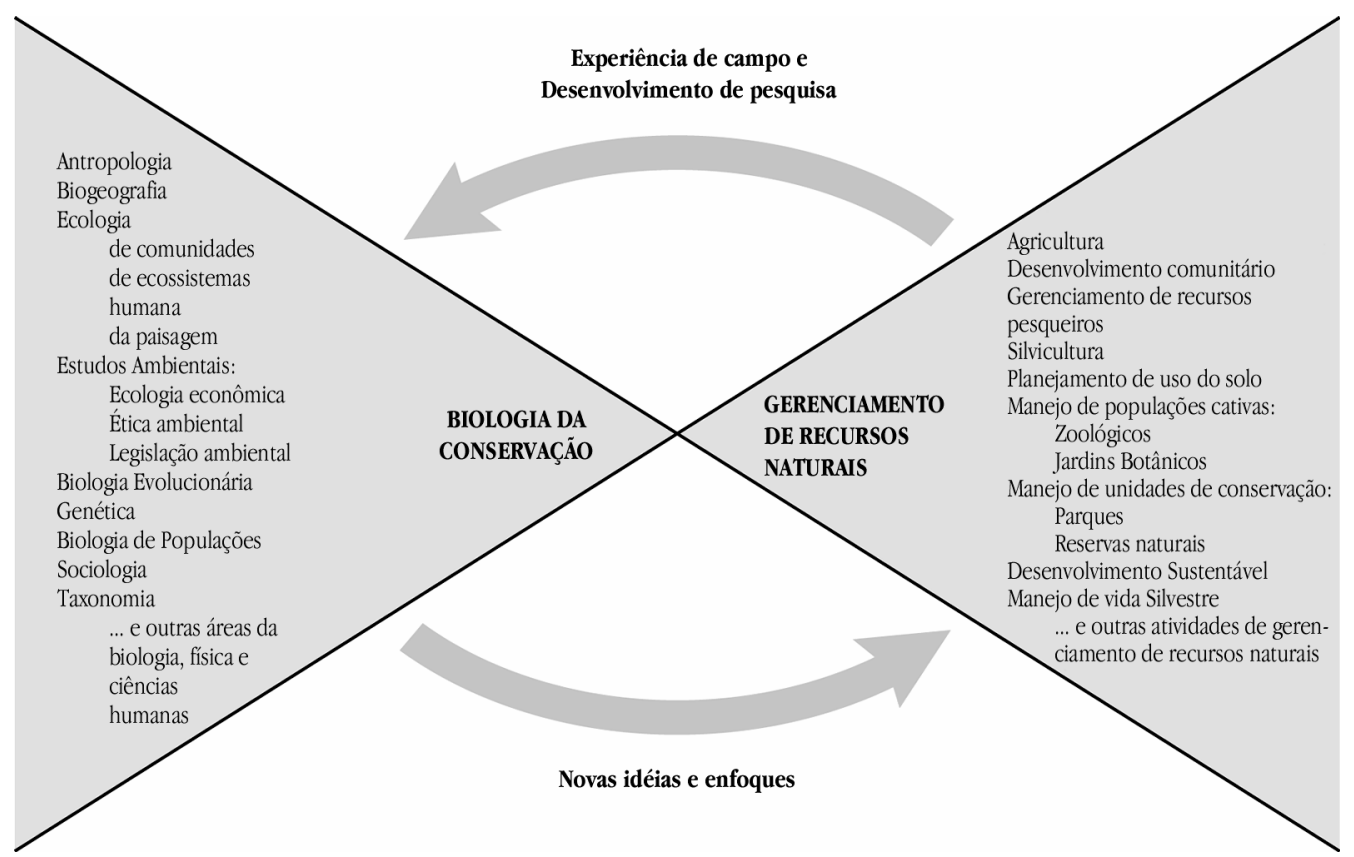

Figura 1 - A Biologia da Conservação realiza uma nova síntese a partir de diversas áreas (esquerda) que oferece princípios e novos enfoques para o manejo de recursos (direita). A experiência acumulada na área por sua vez orienta a direção da pesquisa acadêmica. 
logistas e climatologistas de ecossistemas monitoram as características físicas e biológicas do meio ambiente e desenvolvem modelos para prever as respostas ambientais a distúrbios.

Sob vários aspectos, a biologia da conservação é uma disciplina de crise. As decisões sobre assuntos relativos à conservação são tomadas todos os dias, muitas vezes com informação limitada e fortemente pressionadas pelo tempo. A biologia de conservação tenta fornecer respostas a questões específicas aplicáveis a situações reais. Tais questões são levantadas no processo de determinar as melhores estratégias para proteger espécies raras, conceber reservas naturais, iniciar programas de reprodução para manter a variação genética de pequenas populações e harmonizar as preocupações conservacionistas com as necessidades do povo e governo locais. Os biólogos e outros conservacionistas de áreas afins, são pessoas adequadas para fornecer a orientação que os governos, as empresas e o público em geral necessitam quando têm de tomar decisões cruciais. Embora alguns biólogos conservacionistas possam hesitar em fazer recomendações sem ter conhecimento detalhado das especificidades de um caso, a urgência de muitas situações pede decisões com base em determinados princípios fundamentais de biologia.

A biologia da conservação fundamenta-se em alguns pressupostos básicos (SOULÉ, 1985). Esses pressupostos representam um conjunto de asserções éticas e ideológicas que sugerem abordagens científicas e aplicações práticas. Embora nem todas essas asserções sejam aceitas inequivocamente, a aceitação de uma ou duas já é razão suficiente para justificar os esforços em favor da conservação.

1. A diversidade dos organismos é positiva. Em geral, as pessoas gostam da diversidade biológica. As centenas de milhares de pessoas que visitam os zoológicos, parques naturais, jardins botânicos e aquários a cada ano, são prova do interesse do público em geral na diversidade biológica. A variação genética das espécies também tem apelo popular, como é demonstrado nas exposições de cães e gatos, exposições agropecuárias e de flores. Tem-se especulado, inclusive, que os seres humanos têm uma predisposição genética para gostar da diversidade biológica, chamada biofilia (WILSON, 1984; KELLERT e WILSON, 1993). A biofilia teria sido vantajosa para o estilo de vida "caça e coleta" que o ser humano viveu durante centenas de milhares de anos antes da invenção da agricultura. Uma grande diversidade biológica teria lhe proporcionado uma variedade de alimentos e outros recursos, protegendo-o das catástrofes naturais e da fome.

2. A extinção prematura de populações e espécies é negativa. A extinção de espécies e populações como conseqüência de processos naturais é um acontecimento normal. Através dos milênios do tempo geológico, as extinções das espécies têm sido equilibradas pela evolução de novas espécies. Da mesma forma, a perda local de uma população é geralmente compensada pelo estabelecimento de uma nova população através de dispersão. Entretanto, a atividade humana aumentou mil vezes o índice de extinção. No século vinte, virtualmente todas as centenas de extinções conhecidas de espécies de vertebrados, assim como os presumíveis milhares de extinções de espécies de invertebrados, foram causadas pelo ser humano.

3. A complexidade ecológica é positiva. Muitas das propriedades mais interessantes da diversidade biológica aparecem apenas em ambientes naturais. Por exemplo, as relações ecológicas e de coevolução existentes entre as flores tropicais, beija-flores e ácaros que vivem nas flores. Os ácaros utilizam os bicos dos beija-flores como um "veículo de transporte" para ir de flor em flor (COLWELL, 1986). Tais relacionamentos nunca teriam sido descobertos se os animais e as plantas estivessem morando isoladamente em zoológicos e jardins botânicos. As estratégias fascinantes de animais do deserto para obter água não teriam sido conhecidas se os animais estivessem vivendo em jaulas com água à vontade. Embora seja possível preservar a diversidade biológica das 
espécies em zoológicos e jardins, a complexidade ecológica que existe nas comunidades naturais estaria em grande parte perdida.

4. A evolução é positiva. A adaptação evolucionária é o processo que eventualmente leva a novas espécies e ao aumento da diversidade biológica. Portanto, permitir as populações evoluir "in-situ" é positivo. As atividades humanas que limitam a habilidade das populações de evoluir, tais como reduzir severamente o tamanho de uma população de espécies através da extração excessiva, são negativas.

5. A diversidade biológica tem valor em si. As espécies têm seu próprio valor, independentemente de seu valor material para a sociedade humana. Este valor é conferido pela sua história evolucionária e funções ecológicas únicas e também pela sua própria existência.

\section{3) A Biologia da Conservação no Brasil}

O Brasil é um país atípico em termos de conservação de espécies. Somos tão extensos como EUA, Rússia, Austrália, China e Canadá. Diferentemente destes, estamos localizados em uma área com grande riqueza de espécies (Figura 2), e temos também poucos recursos para conserva-las. Então, conservar espécies no Brasil significa lidar com áreas extensas, muitas espécies, poucos recursos e um grande número de pessoas sem acesso a nutrição e educação e saúde, que freqüentemente se reflete em mais problemas de conservação.

Historicamente, a conservação brasileira evoluiu da preocupação estética (criação do Parque Nacional do Iguaçu e Itatiaia, na década de 1930), para a preocupação com espécies, (Parque do Pau-Brasil, Parque Nacional de Emas, Parque Estadual das Lauráceas, etc.), passando para a ênfase em con- servação de comunidades (Estações Ecológicas) e daí para a promoção social das pessoas que vivem no interior ou entorno destas unidades de conservação, como no caso das Reservas Extrativistas. (WEY DE BRITO, 1998). Esta sucessão de enfoques é bastante similar àquela ocorrida em países mais antigos. Até os anos 90, o Brasil instalou uma densa rede de Unidades de Conservação (Figura 3) cuja efetividade é discutível, ou por serem parques que somente existem no papel, ou porque sua situação fundiária mal resolvida ameaça sua existência, ou porque o modo como estas unidades são administradas não lhes confere a agilidade necessária para interagir com seu entorno. Nos anos 90, o aparecimento de projetos com objetivos específicos (TAMAR, Peixe Boi, Muriqui, Mico Leão Dourado, entre outros) têm liderado as iniciativas na conservação brasileira, por conseguir combinar dinamismo com liberdade da estrutura burocrática governamental. Muitos destes projetos têm também conseguido trabalhar em conjunto com o estado, se tornando uma força organizadora para a burocracia estatal. $\mathrm{O}$ traço mais importante destes projetos é conseguir apresentar soluções inovadoras para a constelação de obstáculos à conservação, muitas delas desenvolvidas em conjunto com as comunidades diretamente relacionadas ao problema.

A conservação no Brasil deve seguir caminhos diferentes daqueles dos países mais antigos (com exceção da Austrália, que é mais nova), também porque a nossa degradação é mais recente. Deste modo, não será necessário trilhar todo o caminho de degradação e restauração que estes países passaram; é possível "cortar caminho" em direção a conservação, além de combinar soluções originadas em diferentes situações. 


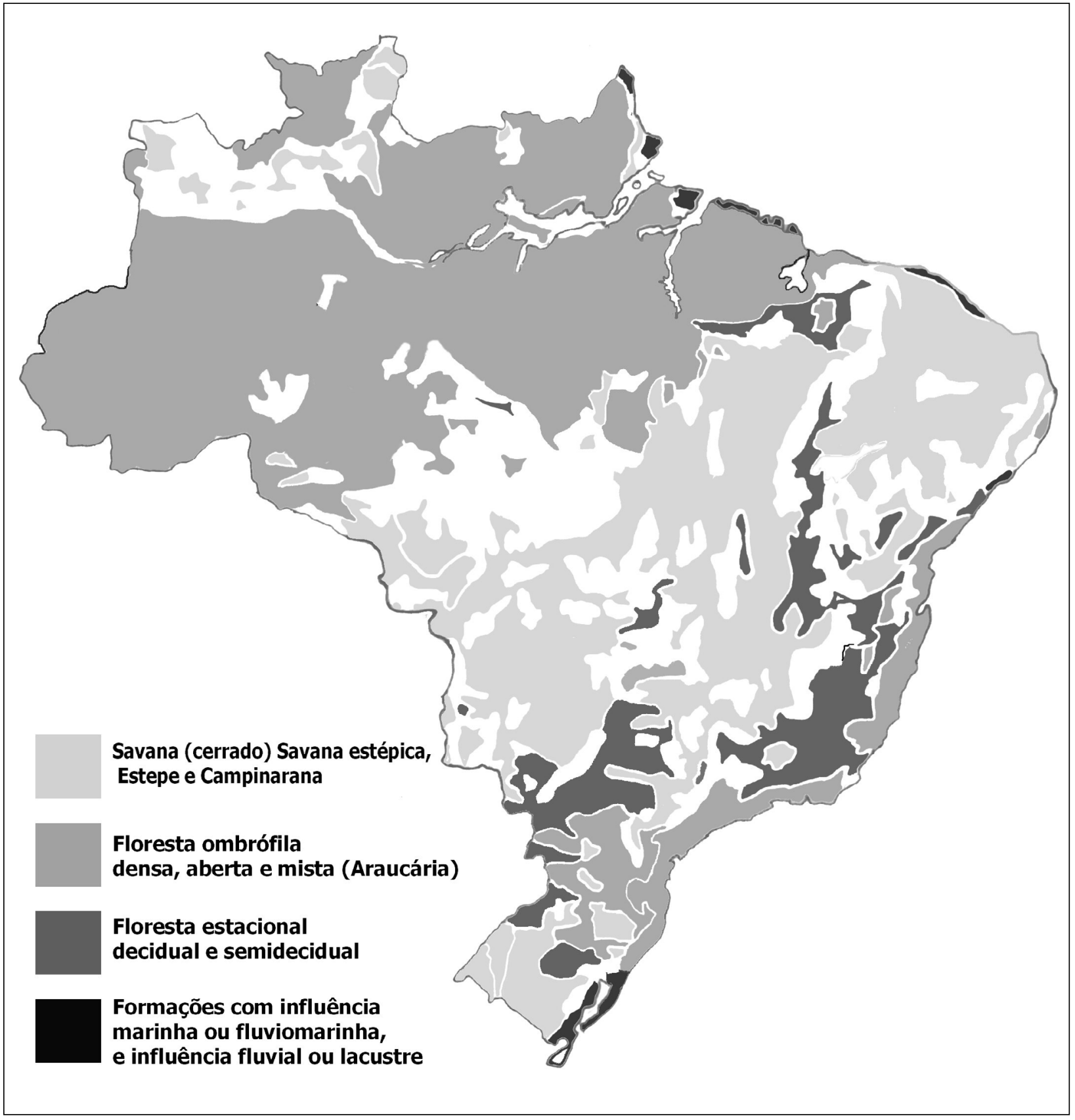

Figura 2 - O Brasil possui uma diversidade inigualável de espécies. Cada um dos biomas apresentados possui alta diversidade alfa e beta. A diversidade gama também é alta, em função da presença de diferentes biomas. (Fonte IBGE, 1998) 


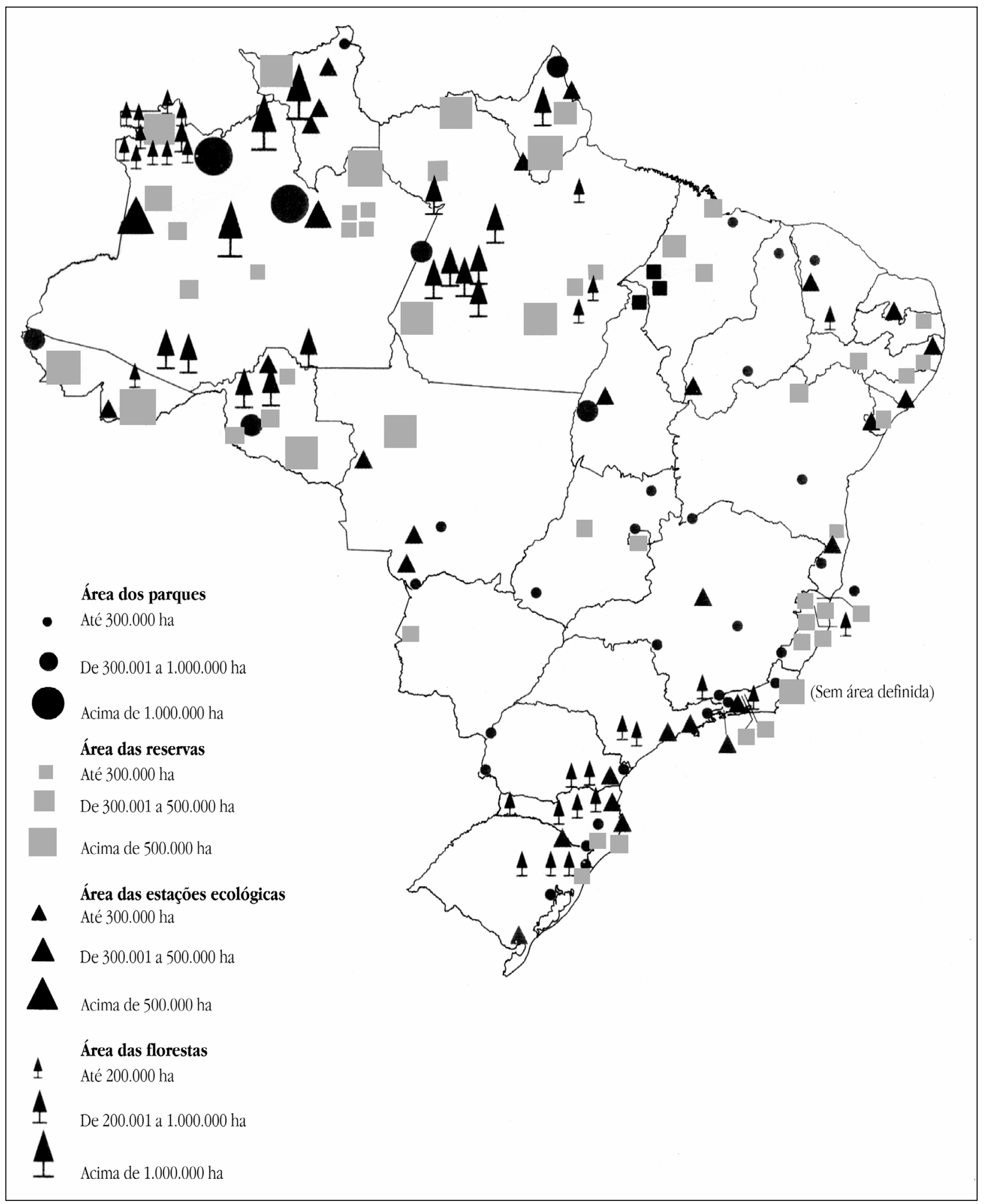

Figura 3 - Unidades de conservação federais (Fonte: IBGE, 1998) 
Algumas questões cruciais em conservação

- Espécies ou comunidades?

Diferentes situações sociais, econômicas e biológicas sugerem diferentes soluções para a conservação.

É possível concentrar os esforços de conservação para a proteção de espécies cujas populações encontram-se em declínio e ameaçadas de extinção. Neste caso, os biólogos de conservação devem determinar a estabilidade das populações em determinadas circunstâncias, a fim de preservar as espécies nas condições impostas pela ação do homem. Conseguiria a população de uma espécie ameaçada sobreviver, ou até mesmo aumentar se mantida em uma reserva natural? Ou a espécie está em declínio, e necessita de atenção especial para que não se torne extinta?

Um grande exemplo de programa de conservação de espécies, é o projeto TAMAR Tartarugas Marinhas, que nasceu com o propósito de conhecer quais espécies ocorriam no litoral brasileiro, e hoje possui 21 bases no litoral brasileiro, onde a conservação das tartarugas é realizada por meio de um trabalho além de biológico, também econômico e social.

É possível também concentrar estes esforços para a conservação de comunidades biológicas intactas. Este é o modo mais eficiente de preservação da diversidade biológica como um todo. Como o Brasil tem recursos e conhecimento suficientes para manter em cativeiro somente uma pequena parcela das espécies do País (e do mundo), esta é a única forma de se preservar espécies em larga escala. As comunidades biológicas podem ser preservadas através do estabelecimento de áreas protegidas, implementação de medidas de conservação fora das áreas protegidas, e restauração das comunidades biológicas em habitats degradados. Um exemplo de conservação de comunidades, é a Reserva de Desenvolvimento Sustentável Mamirauá, onde uma área de 1.124.000 ha na confluência dos rios Solimões e Japurá está sendo conservada em função de possuir um regime de cheias atípico, e um alto grau de endemismos.
Apesar do contexto brasileiro (riqueza de espécies e pobreza de capital) sugerir a conservação de comunidades como estratégia geral algumas espécies exigem cuidados especiais por serem especialmente suscetíveis ao impacto humano. $\mathrm{O}$ altíssimo risco de extinção a que estão sujeitos os grandes predadores e primatas, por exemplo, sugere que nestes casos utilizemos métodos de conservação de espécies, mesmo que não possível a conservação dos seus habitats neste momento. Uma outra situação em que a conservação enfocada em espécies pode ser útil é o caso das espécies carismáticas. Espécies como o Uacari (Figura 4), primata endêmico do Mamirauá, ou o mico leão dourado, podem ser usados como instrumentos para viabilizar a conservação de comunidades inteiras, por meio da simpatia que eles geram com as pessoas. Neste caso, no entanto, é necessário que este meio (a simplificação de um conceito biológico complexo, como a sustentabilidade de comunidades) não entre em conflito com o fim (a conservação de uma comunidade). Em algumas situações, pode não ficar claro para as pessoas, que a espécie, seja ela qual for, não pode ser adequadamente conservada isolada de sua comunidade.

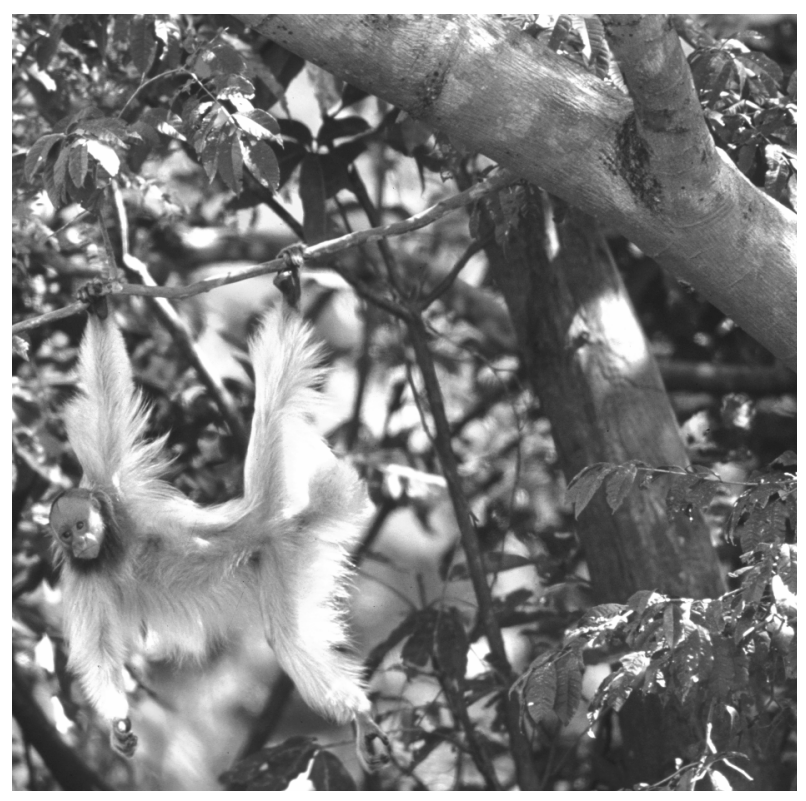

Figura 4 - O Uacari (Cacajao calvus calvus) é uma espécie carismática, cujo interesse para sua conservação serviu para catalizar a conservação na região do Mamirauá, no Amazonas. 
- Proteção ou manejo?

A criação do Parque Yellowstone, em 1872, nos EUA deu grande impulso ao conceito de se escolher áreas que permaneceriam ainda não ocupadas pelo homem (ainda que o Yellowstone não tenha sido a primeira reserva de proteção criada). Um outro conceito de conservação teve início na Europa, principalmente na Inglaterra, onde a falta de grandes áreas desocupadas conduziu os esforços de conservação em direção ao manejo ou uso sustentável de áreas já ocupadas pelo homem.

O Brasil utilizou ambos conceitos de conservação, em função dos vários contextos das suas unidades de conservação, e da sua preocupação tardia com o assunto, que afora todas as desvantagens, nos permiti utilizar a experiência alheia. A legislação brasileira já prevê modalidades de unidades de conservação como Áreas de Proteção Ambiental, Reservas Extrativistas e Reservas de Desenvolvimento Sustentável, que enfatizam o conceito de manejo ou uso sustentável de áreas e aquela s que enfatizam a proteção integral, como Estações Ecológicas, Parques Nacionais e Reservas Particulares do Patrimônio Natural.

Alguns condicionantes regionais determinam se a concepção de uma unidade de conservação deverá enfatizar a proteção integral ou o manejo sustentável.

A proximidade de grandes adensamentos urbanos, como na Estação Ecológica da Juréia-Itatins (próxima de São Paulo) e Parque Nacional da Tijuca (dentro do Rio de Janeiro) implica em grandes pressões humanas, que poderão ser acomodadas pela unidade de conservação, dependendo do valor biológico da área e da natureza das pressões ao redor da Unidade de Conservação. Na Estação Ecológica da Juréia, que é o último grande remanescente de Mata Atlântica na região, optou-se por manter os grupos de caiçaras que já habitavam seu interior e de impedir ao máximo a entrada de turistas da Capital, o que durante muitos anos foi feito pelo exército brasileiro, ainda antes que a área se tornasse uma Estação Ecológica. A Juréia é portanto uma unidade voltada para a proteção integral. No caso do Parque Nacional da Tijuca, o seu valor biológico não é tão alto, já que se trata em grande parte de uma área restaurada em que não houve muito cuidado com as espécies reintroduzidas. Não obstante, a Tijuca tem um grande valor histórico, paisagístico, cênico e educacional para o Rio de Janeiro, razão pela qual foi construída (em muitos casos restaurada) toda uma estrutura de visitação dentro do Parque. A Tijuca é portanto uma unidade de conservação voltada para o manejo sustentável. Uma outra idéia de área manejada é a dos corredores ecológicos, onde áreas, algumas até extensas, são manejadas de modo a melhorar sua conservação e com isso servirem para aumentar o fluxo gênico na paisagem. Apesar de não existir nenhum exemplo concreto no Brasil, existem vários projetos neste sentido, entre eles o corredor do descobrimento (Figura 5).

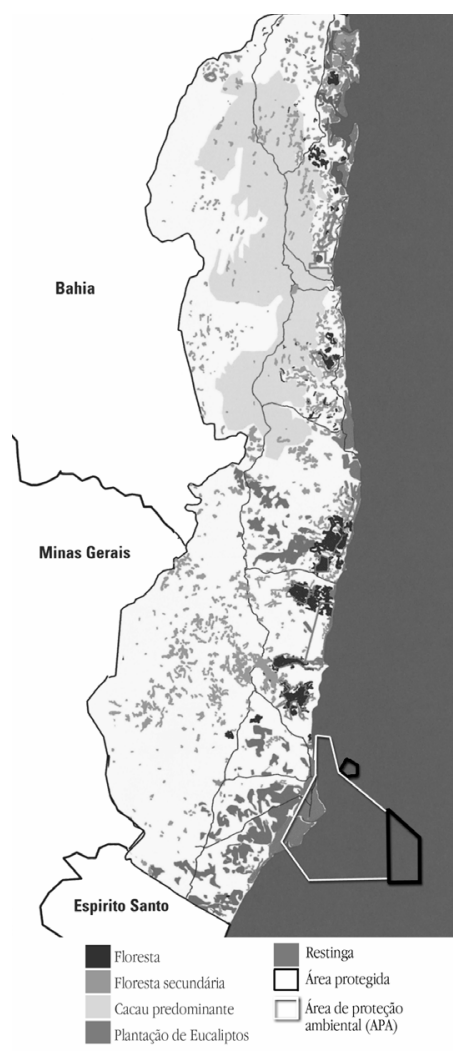

Figura 5 - O Corredor do descobrimento. Esta nova estratégia em implantação pela Conservation International e Fundação Biodiversitas integra reservas voltadas para a preservação e manejo, com áreas privadas, visando a maximização do uso dos recursos disponíveis para conservação (Fonte Cabs, 2000) 
Projetos de conservação bem sucedidos no Brasil

- O projeto TAMAR (Tartarugas Marinhas), em atividade desde 1980, levantou inicialmente as muitas ameaças que as tartarugas sofrem em seu ambiente natural. Durante anos, as tartarugas foram capturadas por pescadores e caiçaras. Essa coleta obviamente não levava em conta estimativas de densidade de população ou época de desova. Um aspecto da história natural das tartarugas é importante para entendermos o efeito dessa coleta. As tartarugas vêm à praia para colocar seus ovos na areia. Fora da água, as tartarugas são facilmente capturadas. Matar uma fêmea nesse momento significa matar um indivíduo adulto, a prole que está para nascer e as outras proles que nasceriam posteriormente. O método normalmente utilizado para matar as tartarugas é virá-las de dorso e deixá-las morrer à míngua. Também na praia, as tartarugas sofrem com a iluminação artificial. Os filhotes possuem fototropismo positivo. Eles saem do ninho e buscam a claridade do horizonte para encontrar o mar. Se houver luzes próximas, os filhotes irão na direção oposta ao mar e reduzirão suas chances de sobrevivência. Quanto mais tempo o filhote demorar para chegar à água, maiores serão as chances dele ser predado por aves aquáticas, caranguejos ou até animais domésticos. Tráfego na praia é outra ameaça para a nidificação das tartarugas. Sendo perturbadas, elas podem retornar para o mar sem botar os ovos.

A construção de casas e prédios à beira mar, consiste também uma ameaça às tartarugas. Ao construir à beira-mar, impedimos a insolação da praia. O sexo das tartarugas não é definido na concepção, como nos mamíferos; se a temperatura da areia for mais quente nascerão mais fêmeas, e se for mais fria nascerão mais machos. Portanto o sombreamento das praias potencialmente aumenta a proporção de machos nas populações de tartarugas.

O projeto TAMAR também levantou que as redes de pesca são grandes ameaças às tartarugas. As tartarugas possuem pulmões. Apesar de conseguirem permanecer por até horas embaixo da água, elas podem morrer afogadas no caso de não conseguir se desvencilhar de uma rede de pesca. Os pescadores costumavam devolver ao mar as tartarugas que vinham com a rede, desavisadamente, assim, terminando de matá-las.

Ao final dos anos 70, todas estas ameaças eram desconhecidas, assim como era também desconhecido o ciclo de vida das tartarugas. Não existiam programas de conservação marinha no Brasil.

Uma saída possível seria maldizer os pescadores e caiçaras, ou aplicar medidas punitivas, ou ainda escolher algum detalhe biológico da espécie e escrever inúmeras teses e artigos científicos, esquecendo do seu contexto. Essas soluções, freqüentemente adotadas, têm sido pouco positivas para a conservação das espécies.

A partir da diagnose inicial, em 1982 o projeto TAMAR passou a proteger três locais principais de desova: Praia dos Comboios (Espírito Santo), Praia do Forte (Bahia) e Pirambu (Sergipe). Hoje o projeto TAMAR protege $1.100 \mathrm{~km}$ de costas, divididos em 21 estações (Figura 6). Em 1999, 8.000 ninhos foram protegidos, envolvendo aproximadamente 360.000 filhotes de tartaruga. Setenta por cento desses ninhos foram mantidos “in-situ”, ou seja, na própria areia da praia, evitando assim possíveis alterações na taxa de sexo das espécies.

Os benefícios do projeto Tamar não se limitam às populações de tartarugas. O projeto também implantou uma nova relação com a comunidade local, onde, mais do que a espécie enfocada, interessa também às pessoas envolvidas. $\mathrm{O}$ projeto é um modelo de empreendedorismo para outras iniciativas ambientais. Cinco grandes instituições subvencionam o projeto, além de algumas fontes próprias de renda.

Pescadores e moradores locais perfazem a grande maioria dos 400 funcionários do TAMAR. Eles são responsáveis pela marcação de fêmeas, coleta e transporte de ovos. Apesar do pagamento de moradores locais colocar algumas dúvidas sobre a manutenção do trabalho após o fim do projeto, a ligação 
entre o projeto e a comunidade é fundamental tanto para levar o conceito de conservação para a comunidade local, como para manter o projeto em contato com a realidade da comunidade.

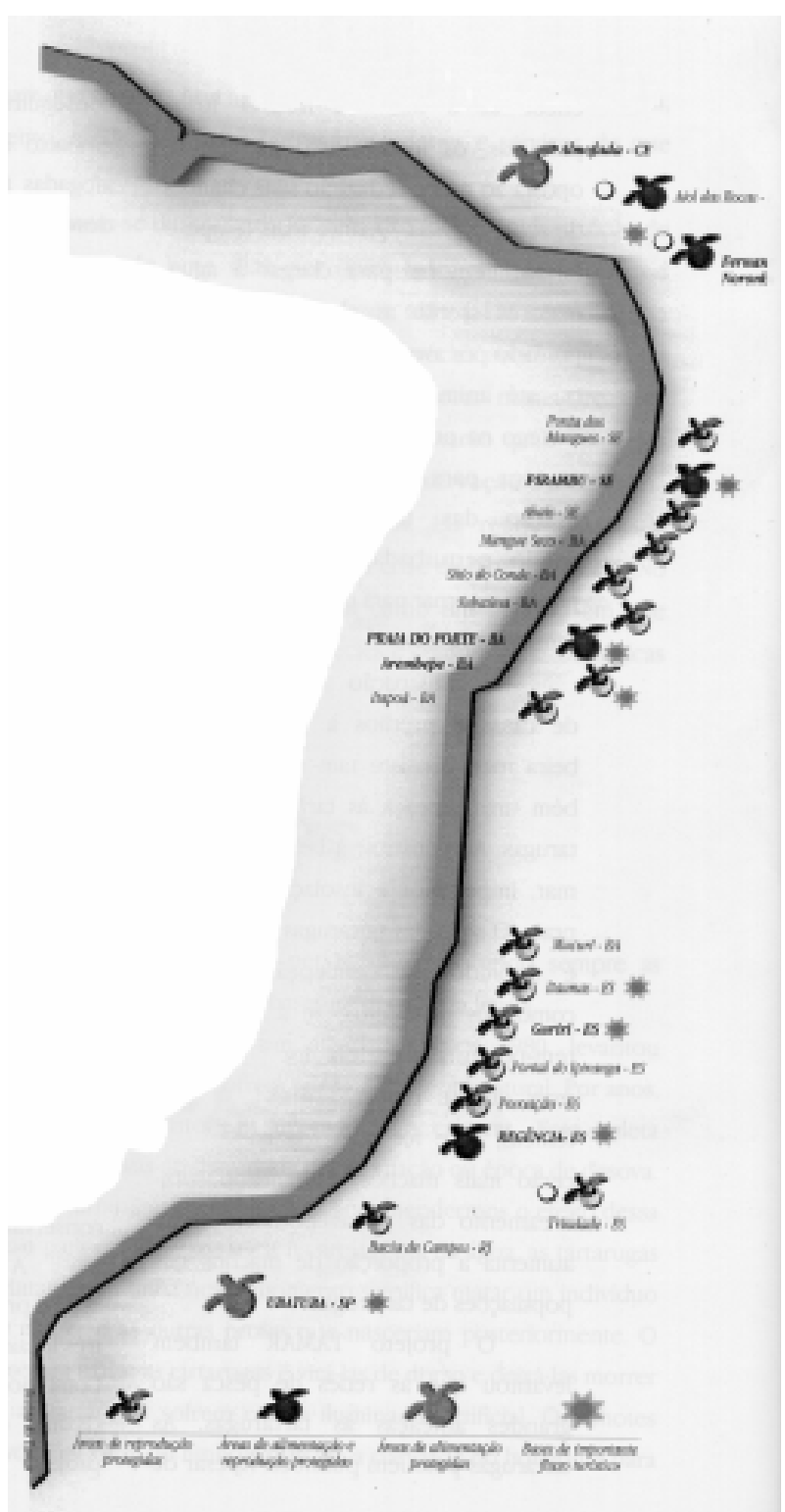

Figura 6 - Localização das 21 bases do projeto.

Além do pagamento direto, o TAMAR mantém creches, uma confecção e um programa de palestras em escolas locais. $\mathrm{O}$ objetivo é conservar as tartarugas marinhas com um benefício correspondente à comunidade local (MARCOVALDI e MARCOVALDI, 1999).
Recentemente o projeto também tem se preocupado com os moradores das grandes cidades. Apesar de não estarem envolvidos direta-mente com o problema, são os moradores das grandes cidades que divulgam o projeto, levando o conceito de conservação ao país como um todo. Estão sendo oferecidos estágios para universitários e programas voltados para visitação turística. Meses após voltar da praia, onde visitaram um desses programas, Yasmin (6 anos) e Arthur (9 anos), paulistanos, espontaneamente fizeram cinco esculturas de tartarugas em sua escola, o mesmo número de espécies que existe no Brasil . As tartarugas marinhas certamente terão um espaço no futuro mundo de Yasmin e Arthur.

As lições para a biologia da conservação são claras: atacando o problema a partir de vários ângulos, os pesquisadores podem trabalhar os problemas econômicos, sociológicos e gerenciais que ameaçam as espécies.

\section{- A Reserva de Desenvolvimento Sustentá-} vel Mamirauá é um exemplo de unidade de conservação bem manejada. O histórico desta unidade de conservação data de 1983, quando o Dr. Marcio Ayres realizou sua tese de doutorado sobre a conservação do Uacari (Cacajao calvus calvus) ( $\mathrm{Fi}$ gura 4), que é endêmico da região. Em 1990, após cinco anos de extensas discussões com os governos federal e estadual, foi criada a Estação Ecológica Mamirauá, situada na confluência dos rios Solimões e Japurá, com 1.124.000 ha.

A característica mais marcante de Mamirauá é ser uma área de várzea, ou uma floresta inundável. O regime de cheias do Solimões determina quanto da reserva será inundada, e quanto estará seca, e por isso é o fator mais importante para a vida silvestre na área. Até mesmo o relevo é determinado pela deposição e erosão de sedimentos, causadas pelas cheias.

Este ambiente raro faz com que Mamirauá seja caracterizada muito mais pelo alto grau de endemismo do que pela alta diversidade, já que poucas espécies 
estão adaptadas a este ambiente raro. Não obstante, a grande variação sazonal e diversidade de ambientes aquáticos faz com que Mamirauá tenha o maior número de espécies de peixes (300) já registrado em uma várzea.

A colonização humana recente em Mamirauá data do início do século. Atualmente, existem poucas comunidades indígenas na região, e mesmo estas, apresentam bastante miscigenação, tanto cultural quanto genética. A maior parte dos assentamentos humanos em Mamirauá está situada ao longo dos rios Japurá e Solimões. A natureza dinâmica do ambiente produz um padrão de ocupação humana que também é caracterizado pela mobilidade. Conforme muda o relevo, mudam os assentamentos. Até mesmo o gado é criado em balsas flutuantes.

A qualidade de vida das pessoas que vivem em Mamirauá era incompatível com a definição legal de Estação Ecológica, que não prevê nenhum uso direto, somente conservação e pesquisa, e mesmo esta é restrita a $10 \%$ da área da Estação. A implantação de uma unidade de conservação nestes moldes contaria com a oposição dos moradores, que praticam vários tipos de extração na área.

Em 1996, após quatro anos de projetos na área, o Governo Estadual do Amazonas reclassificou Mamirauá como uma Reserva de Desenvolvimento Sustentável. Neste mesmo ano, o plano de Manejo da Reserva passou a ser implementado. Ele prevê três programas principais: Extensão e Participação, Pesquisa e Monitoramento e Administração. O programa de extensão é dividido em extensão ecológica e extensão econômica. A pesquisa e monitoramento visam ao manejo da reserva, à informação do público e à viabilização do desenvolvimento sustentável.

A base da Reserva, em Tefé-AM, se parece com um formigueiro em plena atividade. Nela coexistem a central administrativa, a loja de lembranças, um estúdio de rádio e TV, a cozinha, garagem, dormitórios, centro de informática, sala de reuniões, biblioteca, freezers com material de pesquisa, entre outros. Um time jovem e extremamente motivado adminis- tra a reserva com organização impecável. A estrutura humana e material que o Dr. Marcio Ayres conseguiu montar em Mamirauá se deve não só a sua capacidade administrativa, mas também a sua agilidade em captar recursos para a Reserva.

Inúmeras entidades colaboram com a reserva, tanto brasileiras quanto estrangeiras. Um flutuante com todos os confortos da cidade grande está sendo construído para receber turistas estrangeiros a preços diferenciados, o que irá auxiliar a manutenção da reserva a longo prazo. No entanto, no menos confortável flutuante dos pesquisadores, é possível experimentar Mamirauá mais de perto, ouvir as estórias dos guias, dormir em redes e acordar no meio da noite com o guinchado alegre de um boto embaixo da sua janela.

Mamirauá prova que para implementar projetos práticos, os profissionais de conservação devem se envolver com aspectos financeiros, administrativos e políticos.

\section{O Projeto "Biologia da Conservação"}

A versão brasileira do "Primer on Conservation Biology" começou a tomar forma em 1998 em Boston. Eu e Richard Primack inicialmente queríamos apenas viabilizar a tradução do livro para o Português. Após minha volta para o Brasil e o inicio deste trabalho, ficou cada vez mais claro que a simples tradução do Primer on Conservation Biology até resolveria o problema daqueles estudantes que não lêem inglês, mas que também com isto nós estaríamos perdendo a grande oportunidade de ilustrar a teoria de Biologia da Conservação com exemplos familiares para os brasileiros. As alterações do livro original foram se empilhando até o ponto em que decidimos começar do zero e escrever um novo livro a duas mãos.

Dois anos depois, o novo livro estava bem encaminhado, e já discutíamos com algumas editoras a publicação do Biologia da Conservação. Descobrimos então que a nossa idéia de produzir um livro 
barato e de qualidade não era compatível com a margem de lucro das editoras e distribuidoras. Neste exato momento tivemos um projeto aprovado pela Foundation for Conservation Food and Health que custeou os gastos de editoração e impressão do Biologia da Conservação. A nossa idéia original possivelmente estaria na prancheta até hoje se não tivessemos contado com este empurrão.

O Biologia da Conservação nasceu no dia 10 de junho de 2001, em uma situação insólita. Depois de alguns atrasos da gráfica, nós tivemos que ir lançar o livro sem que ele estivesse pronto. Os funcionários da gráfica adentraram o auditório em meio a palestra de lançamento! A platéia terminou então tomando contato com o livro antes mesmo de nós.

Para distribuir o Biologia da Conservação para um número maior de pessoas nós tivemos que abrir mão (por mais paradoxal que possa parecer) dos maiores distribuidores de livros. Grandes distribuidores de livros trabalham com margens de lucro da ordem de 50 a $60 \%$ do preço de capa. Isto implica que aqueles que escreveram, imprimiram e venderam o livro ficam com menos que a metade do valor do livro. É comum que o distribuidor lucre dez vezes mais com cada livro do que o próprio autor. Para evitar o aumento do preço que a distribuição acarretaria, nós estamos também distribuindo o livro. Quase todos os livros até hoje foram vendidos por livreiros a quem entregamos os livros diretamente, tornando-o com isto mais barato para o estudante.

Os direitos autorais (por menores que sejam) também foram cortados. Desta forma, todo o dinheiro arrecadado com a venda dos livros é gasta para imprimir mais livros.
O Biologia da Conservação portanto, que começou como uma tradução, tornou-se um projeto sustentável de conservação (financeiramente falando), que tem cumprido os seguintes objetivos:

1) Tornar a teoria em Biologia da Conservação acessível aos alunos de graduação;

2) Divulgar os projetos de conservação brasileiros;

3) Estimular que mais autores sigam o mesmo caminho e que com isso mais títulos estejam disponíveis a preços mais baixos.

\section{Bibliografia}

CABS -Center for Applied Biodiversity Science-2000. Planejando Paisagens Sustentáveis A Mata Atlântica Brasileira.

COLWELL, R. K. 1986. Community biology and sexual selection: Lessons from hummingbird flower mites. In T. J. Case e J. Diamond (eds.) Ecological Communities, pp. 406-424. Harper and Row Publishers, New York.

MARCOVALDI M.A.; MARCOVALDI G.G. 1999. Marine turtles of Brazil: the history and structure of Projeto TAMAR-IBAMA Biology Conservation 91: (1) 35-41 NOV

KELLERT, S. R. e E. O. Wilson (eds.). 1993. The Biophilia Hypothesis. Island Press, Washington, D.C.

WILSON, E. O. 1984. Biophilia. Harvard University Press, Cambridge, MA.

PRIMACK, R.; RODRIGUES, E. 2001. Biologia da Conservação. 328 p. Efraim Rodrigues, Londrina

SOULÉ, M. 1985. What is conservation biology? BioScience 35: 727-734.

WEY DE BRITO, M.C. 1998. Unidades de conservação: intenções e resultados Annablume. 